\title{
Botanical Agent LEAC-102
}

National Cancer Institute

\section{Source}

National Cancer Institute. Botanical Agent LEAC-102. NCI Thesaurus. Code C129711.

A botanical-based formulation derived from the Taiwanese mushroom Antrodia cinnamomea, with potential antineoplastic activity, Upon administration, the components in LEAC-102 may exert cytotoxic effects against cancer cells. 